\title{
Calculation of Radiation Protection Quantities and Analysis of Astronaut Orientation Dependence
}

\author{
Martha S. Clowdsley ${ }^{1}$ \\ NASA Langley Research Center, Hampton, VA, 23681 \\ John E. Nealy ${ }^{2}$ \\ Old Dominion University, Norfolk, VA, 23529 \\ William Atwell ${ }^{3}$ \\ The Boeing Company, Houston, TX, 77059 \\ Brooke M. Anderson ${ }^{4}$ \\ NASA Langley Research Center, Hampton, VA, 23681 \\ Nathan J. Luetke ${ }^{5}$ \\ Lockheed Martin, Hampton, VA, 23681 \\ and \\ John W. Wilson ${ }^{6}$ \\ NASA Langley Research Center, Hampton, VA, Zip 23681
}

\begin{abstract}
Health risk to astronauts due to exposure to ionizing radiation is a primary concern for exploration missions and may become the limiting factor for long duration missions. Methodologies for evaluating this risk in terms of radiation protection quantities such as dose, dose equivalent, gray equivalent, and effective dose are described. Environment models (galactic cosmic ray and solar particle event), vehicle/habitat geometry models, human geometry models, and transport codes are discussed and sample calculations for possible lunar and Mars missions are used as demonstrations. The dependence of astronaut health risk, in terms of dosimetric quantities, on astronaut orientation within a habitat is also examined. Previous work using a space station type module exposed to a proton spectrum modeling the October 1989 solar particle event showed that reorienting the astronaut within the module could change the calculated dose equivalent by a factor of two or more. Here the dose equivalent to various body tissues and the whole body effective dose due to both galactic cosmic rays and a solar particle event are calculated for a male astronaut in two different orientations, vertical and horizontal, in a representative lunar habitat. These calculations also show that the dose equivalent at some body locations resulting from a solar particle event can vary by a factor of two or more, but that the dose equivalent due to galactic cosmic rays has a much smaller $(<15 \%)$ dependence on astronaut orientation.
\end{abstract}

${ }^{1}$ Physicist, Durability, Damage Tolerance, and Reliability Branch, M.S. 188E.

${ }^{2}$ Research Professor, Mathematics Department.

${ }^{3}$ Technical Fellow, NASA Systems, 3700 Bay Area Bldg. Office: 2D608, AIAA Associate Fellow.

${ }^{4}$ Aerospace Engineer, Structural and Thermal Systems Branch, M.S. 431.

${ }^{5}$ Engineer, Lockheed Martin Space Operations, 188E.

${ }^{6}$ Senior Research Scientist, Durability, Damage Tolerance, and Reliability Branch, M.S. 188E. 


\section{Nomenclature}

$\begin{array}{ll}A_{j} & =\text { atomic weight of type } j \text { particles } \\ D & =\text { dose } \\ E & =\text { effective dose } \\ H & =\text { dose equivalent } \\ G & =\text { gray equivalent } \\ L & =\text { linear energy transfer } \\ Q & =\text { quality factor for stochastic biological effects } \\ R_{i} & =\text { relative biological effectiveness number } \\ \sigma_{j} & =\text { media macroscopic cross section for removal of type } j \text { particles } \\ \sigma_{j k} & =\text { production cross-section } \\ \mathrm{S}_{j} & =\text { stopping power for type } j \text { particles } \\ \phi_{j} & =\text { flux density of type } j \text { particles } \\ w_{T} & =\text { effective dose tissue weighting factor }\end{array}$

\section{Introduction}

$\mathrm{T}_{\mathrm{r}}$

HERE are several requirements for calculating radiation exposure on space exploration missions: external radiation environments for each mission segment, vehicle and/or habitat shielding models for each mission segment, human body geometry models, radiation transport codes, methods of converting particle spectra into useful quantities for evaluating risk, and some measure of how much exposure is too much. Most of these requirements exist in the form of computer codes or models. The total mission exposure is cumulative and is calculated by summing the exposures for each mission segment.

Dosimetric quantities have been calculated for a long duration lunar surface mission and a representative Mars mission. In both cases, a solar minimum galactic cosmic ray environment was used to provide a "worst case" analysis and the additional exposure provided by a large solar particle event was calculated. For the lunar surface mission calculation, exposure for a 180 day surface stay was calculated using a representative lunar habitat model and a human body model representing an average male. Here, the dose equivalent at several body locations and the whole body effective dose were calculated for an astronaut with two different orientations, vertical and horizontal, providing a rough estimate of the effect of reorienting the astronaut on radiation exposure. Exposure calculations were not performed for a lunar transit vehicle, but calculations from previous studies are referenced. For the Mars mission scenario, whole body effective dose was calculated for a male astronaut using a vehicle which utilizes the inflatable Transhab for astronaut habitation for the near Earth to Mars orbit and Mars orbit to near Earth transit legs of the mission and the same habitat that was used for the lunar surface calculation for the Mars surface stay segment.

This document provides a description of a methodology used by NASA to evaluate astronaut risk due to space radiation exposure for proposed exploration missions. This description includes an explanation of the tools required (computer codes and models) and some discussion about dosimetric quantities used to compute health risk. Space radiation environment models are described in section II, radiation transport codes are described in section III, and radiation protection quantities such as dose equivalent and gray equivalent are discussed in section IV. In section V, rough estimates of astronaut radiation exposure for lunar and Mars missions are provided through sample calculations applying this methodology to representative habitat models and mission scenarios. This section also provides a preliminary examination of the effect of reorienting an astronaut within a habitat on computed risk quantities.

\section{Environment Models}

The first requirement for evaluating space radiation exposure risk is an accurate description of the radiation environment outside the vehicle or habitat. This description should include an energy spectrum for each type of particle found in the environment. In free space, there are two types of environment of concern: galactic cosmic rays (GCR) and large solar particle events (SPE). On or near planetary surfaces, these radiation environments are altered by interactions of free space particles with the planetary atmosphere, if one exists, and planetary surface materials. Planetary magnetic fields, such as the Earth's, will also affect the free space environments by both repelling low energy ions and trapping charged particles (protons and electrons) produced in the atmosphere. At some Earth orbit altitudes $(>1000 \mathrm{~km})$, the intensity of this trapped proton environment could be harmful to both humans and electronics. However, it has been shown that vehicles traverse this region quickly enough to provide minimal exposure to astronauts and electronics. ${ }^{1}$ The environment inside the Earth's magnetic fields is, therefore, 
not examined in this paper. The effects on the radiation environment of localized magnetic fields on the Martian surface are also not evaluated.

\section{A. Galactic Cosmic Rays}

The free space GCR environment is made up of heavy and light charged ions originating outside the solar system. This ever-present environment is modulated by the solar wind and, therefore, varies with distance from the sun and to a larger extent, the solar cycle. Maximum GCR intensity is at solar minimum, when the sun is least active while minimum GCR intensity occurs at solar maximum, when the sun is most active. Short duration exposure to GCR provides little health risk, but longer duration exposure may result in late term effects such as cataracts and cancers. The sample calculations described in this document utilize the 1992 BadhwarO'Neill model ${ }^{2}$ which defines a solar maximum GCR environment and a solar minimum GCR environment at $1 \mathrm{AU}$ as shown in Fig. 1. Here the ions are grouped by charge, Z. The GCR environment for a given day is calculated by interpolating between solar maximum and solar minimum. One method for doing this interpolation utilizes the neutron count measured by the Deep River Neutron Monitor (DRNM). The charged ions making up the free-space GCR environment interact with the atoms making up the Earth's atmosphere in two ways. When an atomic interaction occurs, the charged ion strips an electron from an atom and loses energy in the process. When a nuclear interaction occurs, the charged ion collides with or comes very close to an atom's nucleus. Nuclear collisions often result in the destruction of the original ion and the production of a number of smaller ions and neutrons. The neutron count measured on the Earth's surface, in this case at the Deep River station in Canada, is, therefore, a good predictor of free space GCR intensity, because the number of neutrons produced in the Earth's atmosphere increases when the number of charged ions impinging on this atmosphere increases. Predicted DRNM numbers ${ }^{3}$ have been used since the monitor was turned off in 1995 . Figure 2 demonstrates the inverse relationship between solar activity and GCR intensity by showing measured and predicted DRNM neutron count numbers on the same plot with measured and predicted sun spot numbers.

\section{B. Large Solar Particle Events}

Unlike the GCR environment, solar particle events are isolated events with durations usually measured in hours. Solar particle events occur when a large number of particles, mostly protons, move through the solar system. These events happen during periods of increased solar activity and appear to correspond to large coronal mass ejections. ${ }^{4}$ Large SPE have occurred only rarely, one or two per eleven year solar cycle in the past sixty years, but exposure to a large SPE could be lethal if

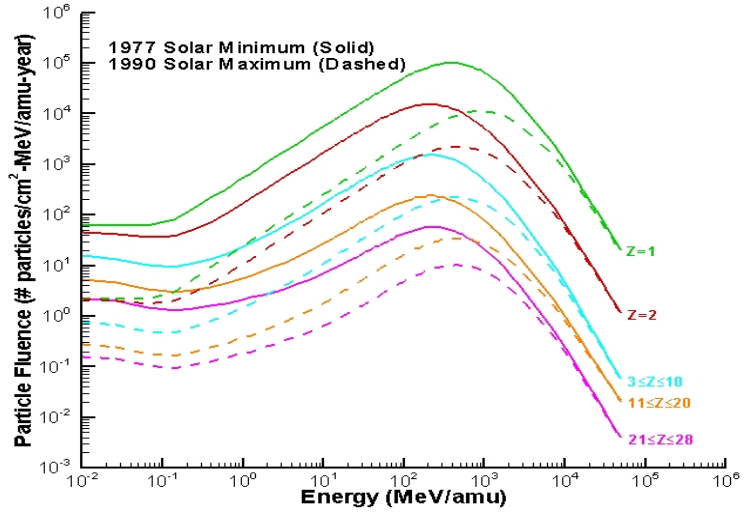

Figure 1. Freespace GCR environment.

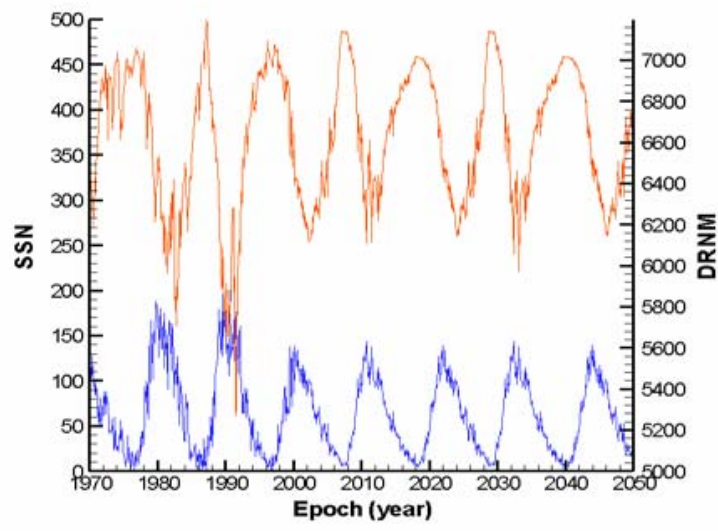

Figure 2. Sunspot number (blue) and DRNM neutron count (red), measured (before 1995) and projected (after 1995).

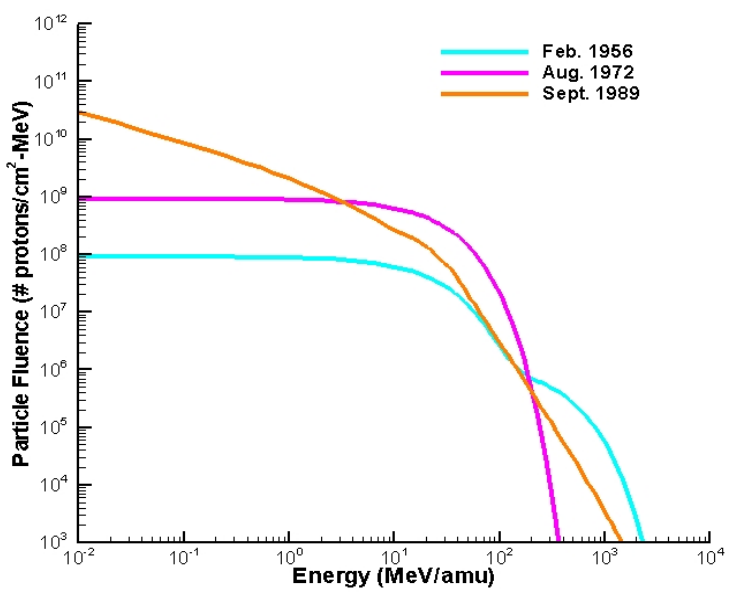

Figure 3. Proton spectra for three historic large solar particle events. 
enough shielding is not provided. The proton spectra for three of the largest historical events are shown in Fig. 3. This plot show how much these events vary. The September 1989 event had a very large number of low energy neutrons, but the August 1972 event had a larger number of the more penetrating neutrons in the 20 to $200 \mathrm{MeV}$ range. It should be noted that the September 1989 event also included a heavy ion contribution. ${ }^{5}$

The definition of a "design basis" SPE for NASA exploration missions has been much debated, and at the time of this writing, remains unresolved. Development of a probabilistic model, in which the size and possibly the spectral shape of the "design basis" SPE depend on mission characteristics, such as duration and time in the solar cycle, has been proposed. It has also been suggested that varying multiples of the proton spectrum incurred during either the August 1972 event or the September 1989 event be used to provide corresponding confidence levels of astronaut protection. The King ${ }^{6}$ model of the August 1972 SPE is used for the analyses described in this document.

\section{Martian and Lunar Environments}

The free space radiation environment is altered by the Martian atmosphere through interactions between the charged ions making up the free space environment and the atoms making up the atmosphere, primarily $\mathrm{CO}_{2}{ }^{7-10}$ The charged ions lose energy due to ionization, and nuclear collisions occur, producing secondary ions as well as neutrons. These charged ions and neutrons also interact with atoms making up the Martian surface material, producing more secondary ions and neutrons. In order for momentum to be conserved, most of the secondary particles produced as a result of nuclear collisions move in the same direction or close to the same direction as the primary particles that produced them, but some lower energy, lighter particles (primarily neutrons) produced in the Martian surface material are scattered back to the surface. Therefore, the environment at any location on the surface at any given time depends on the free space environment at that time, on the altitude of the location (the amount of atmosphere above the surface point), and on the atomic make-up of the material below the surface point (regolith, $\mathrm{H} 2 \mathrm{O}$ ice, $\mathrm{CO} 2$ ice, or some combination). Calculated Mars surface environments for solar maximum and solar minimum are shown in Fig. 4. For these calculations, an atmosphere of $16 \mathrm{~g} / \mathrm{cm}^{2}$ (thickness in $\mathrm{cm}$ scaled by density in $\mathrm{g} / \mathrm{cm}^{3}$ ) of $\mathrm{CO}_{2}$ and a Martian regolith surface material ${ }^{7}$ made up of $58.2 \% \mathrm{SiO}_{2}, 23.7 \% \mathrm{Fe}_{2} \mathrm{O}_{3}, 10.8 \% \mathrm{MgO}$, and $7.3 \% \mathrm{CaO}$ input into the HZETRN transport code. Comparison between Fig. 4 and Fig. 1 shows a neutron component to the surface environment, labeled $Z=0$ in Fig. 4, which is not present in the free space environment shown in Fig. 1 and an increased number of low energy light ions, labeled $Z=1$ and $Z=2$ in both figures, on the Martian surface. Both of theses differences are caused by interactions between the free space ions and the atmosphere and/or surface regolith.

Since the lunar atmosphere is negligible, the free space environment is only affected by the lunar regolith. The charged ion environment on the surface is, therefore, approximately half that of the free space environment due to the surface shadow. The lunar surface environment, however, also has a low energy neutron component, labeled $\mathrm{Z}=0$, made up of neutrons produced during nuclear collisions between free space ions and the atoms making up the lunar regolith, as shown in Fig. 5. The neutron spectrum on the surface of the moon only includes low energy neutrons because only low energy neutrons are scattered back up to the surface.

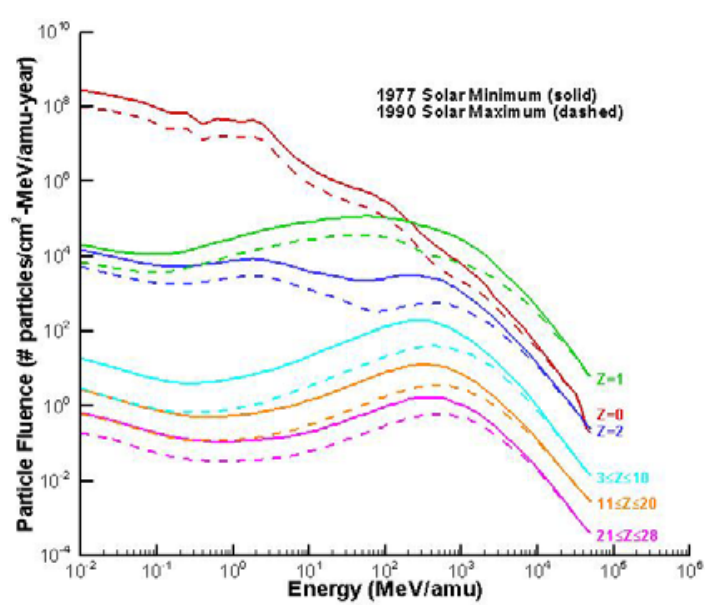

Figure 4. Martian surface environment due to GCR

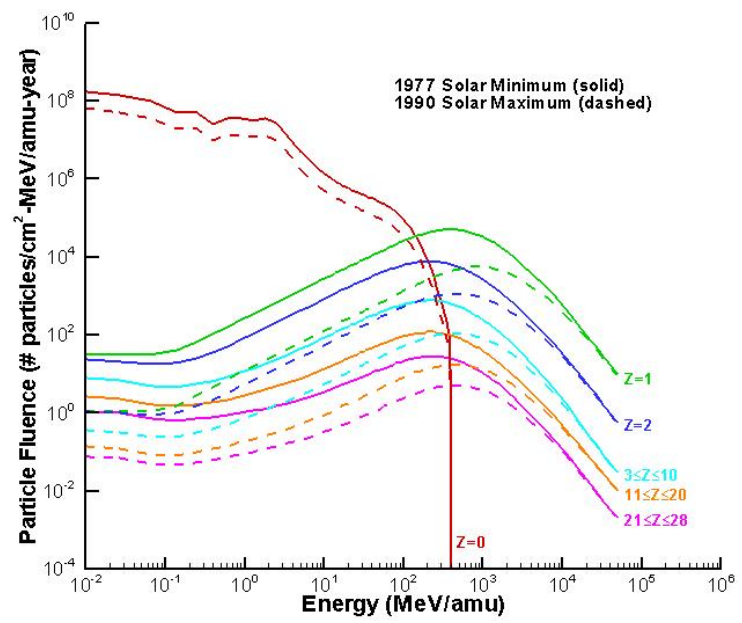

Figure 5. Lunar surface environment due to GCR. 


\section{Radiation Transport Calculations}

In order to calculate the radiation environment at a particular body tissue site at a particular location inside a space habitat at a given time, shielding models for both the astronaut and the habitat are required, as is a space radiation transport code to calculate the transport of the particles in the external environment through the shielding material provided by the habitat and the astronaut's body. There are two types of radiation transport codes, MonteCarlo codes such as MCNPX, ${ }^{11}$ HETC-HEDS, ${ }^{12}$ FLUKA,${ }^{13}$ and GEANT4,${ }^{14,15}$ which use statistical methods, and deterministic codes such as HZETRN, ${ }^{16,17}$ which utilize approximate solutions to the Boltzmann transport equation given in Eq. (1)

$$
\Omega \bullet \nabla \phi_{j}(\mathbf{x}, \Omega, E)=\Sigma \int \sigma_{j k}\left(\Omega, \Omega^{\prime}, E, E^{\prime}\right) \phi_{k}\left(\mathbf{x}, \Omega^{\prime}, E^{\prime}\right) d \Omega^{\prime} d E^{\prime}-\sigma_{j}(E) \phi_{j}(\mathbf{x}, \Omega, E)
$$

where, $\phi_{j}(x, \Omega, E)$ is the flux density of type $j$ particles at point $x$ moving in direction $\Omega$ with energy $E, \sigma_{j}(E)$ is the media macroscopic cross section for removal of type $j$ particles with energy $E$, and $\sigma_{j} k\left(\Omega, \Omega^{\prime}, E, E^{\prime}\right)$ is the cross section for the production of type $j$ particles with energy $E$ moving in direction $\Omega$ due to the atomic or nuclear interaction of a type k particle of energy $E^{\prime}$ and direction $\Omega^{\prime}$ with atoms in the shielding material. The 2005 version of HZETRN ${ }^{17}$ was chosen for the calculations described herein for its computational speed, ease of use, and because HZETRN has been used extensively for both GCR and SPE dosimetric calculations in complex geometries. This codes uses a "straight ahead" approximation in which it is assumed that all secondary particles move in the same directions as the primaries. This reduces the Boltzmann equation to Eq. (2)

$$
\left[\partial \mathrm{x}-\mathrm{A}_{\mathrm{j}}^{-1} \partial \mathrm{E} \operatorname{Sj}(\mathrm{E})+\sigma_{\mathrm{j}}(\mathrm{E})\right] \phi_{\mathrm{j}}(\mathrm{x}, \mathrm{E})=\Sigma \int \sigma_{\mathrm{j} k}\left(\mathrm{E}, \mathrm{E}^{\prime}\right) \phi_{\mathrm{k}}\left(\mathrm{x}, \mathrm{E}^{\prime}\right) \mathrm{dE^{ \prime }}
$$

where $A_{j}$ is the atomic weight of type $j$ particles and $\mathrm{S}_{j}$ is the stopping power for type $j$ particles. This equation is then solved using a marching technique.

In order to calculate the radiation environment at a given point in the body at a particular location in the habitat using HZETRN 2005, both the human body model and the habitat shielding model must be "ray-traced." This "raytracing" is performed by dividing the volume surrounding the dose point into a number of equal solid angles and calculating the thickness of each type of shielding along a ray through each solid angle. HZETRN 2005 can then be used to calculate the transport of the external environment through the material thicknesses along each ray. It should be noted that most CAD models can be converted to shielding thickness models that can be ray traced. Many other transport codes require the user to develop geometry models created by summing simple volumes. For complicated geometries, this can be a time consuming process and can lead to long computation times.

\section{Dosimetric Quantities and Exposure Limits}

\section{A. Dosimetric Quantities}

There are four dosimetric quantities used to calculate radiation exposure by NASA scientists: dose, dose equivalent, gray equivalent, and effective dose. Dose is the energy absorbed per unit mass of material or tissue and is measured in grays $(1 \mathrm{~Gy}=100 \mathrm{rad}=1 \mathrm{~J}$ per $\mathrm{kg})$. Dose can be used in a first order approximation of risk to electronic equipment, but because some types of particles are more damaging to human tissue than others, it does not provide a good measure of risk to astronauts.

For this reason, dose equivalent, $H$, was developed as defined in Eq. (3)

$$
H=\int Q(L) D(L) d L
$$

where $L$ is the linear energy transfer and $Q$ is a quality factor. The quality factor recommended in the International Commission for Radiological Protection (ICRP) report no. $60^{18}$ and adopted by the National Council on Radiation Protection and Measurements (NCRP) ${ }^{19}$ is given in Eq. (4) 


$$
\begin{array}{ll}
Q(L)=1, & L<10 \\
Q(L)=0.32 L-2.2, & 10<L<100 \\
Q(L)=300 L^{-1 / 2}, & L>100
\end{array}
$$

where the linear energy transfer, $\mathrm{L}$, is in $\mathrm{keV} / \mu \mathrm{m}$ and dose equivalent is in sieverts $(1 \mathrm{~Sv}=100 \mathrm{rems})$. The dose equivalent quality factor was developed using cell death and mutation data largely from animal experiments to model stochastic effects and was not ideal for modeling deterministic effects. Thus, the quantity gray equivalent was introduced in NCRP report no. $132^{20}$ and defined in greater detail in NCRP report no. $142 .{ }^{21}$ Gray equivalent, $G_{T}$, for tissue type $T$ is defined in NCRP report no. 142 as

$$
G_{T}=\sum_{i} R_{i} D_{T, i}
$$

where $D_{T, i}$ is the mean absorbed dose to tissue $T$ and $R_{i}$ is the recommended relative biological effectiveness number. The relative biological effectiveness (RBE) numbers defined in NCRP report no. 132 are given in Table 1.

Table 1. Recommended relative biological effectiveness numbers.

\begin{tabular}{|c|c|}
\hline Particle Type & RBE \\
\hline 1 to 5 MeV neutrons & 6.0 \\
\hline 5 to 50 MeV neutrons & 3.5 \\
\hline Heavy ions (e.g. helium, carbon, neon, argon) & 2.5 \\
\hline Protons $>$ 2 MeV & 1.5 \\
\hline
\end{tabular}

It should be noted that the relative biological effectiveness numbers are to be applied to the ambient radiation fields external to the human body but inside the vehicle and/or habitat.

NCRP report no. 132 also defined the quality factor effective dose, $E$, as a better measure of whole body exposure than dose equivalent to blood forming organs, BFO. Effective dose is a weighted average of dose equivalent to various organ and/or tissue types and is defined by Eq. (6) as

$$
E=\Sigma w_{T} H_{T}
$$

where $H_{T}$ is the average dose equivalent to tissue type $T$ and $w_{T}$ is the weighting factor for tissue type $T$. The effective dose weighting factors designated in NCRP report no. 132 are given in Table 2.

Table 2. Effective dose weighting factors, $w_{T}$.

\begin{tabular}{|c|c|c|c|}
\hline $\mathbf{0 . 0 1}$ & $\mathbf{0 . 0 5}$ & $\mathbf{0 . 1 2}$ & $\mathbf{0 . 2 0}$ \\
\hline $\begin{array}{c}\text { Bone } \\
\text { surface }\end{array}$ & Bladder & $\begin{array}{c}\text { Bone } \\
\text { marrow }\end{array}$ & Gonads \\
\hline skin & Breast & Colon & \\
\hline & Liver & Lung & \\
\hline & Esophagus & Stomach & \\
\hline & Thyroid & & \\
\hline & Remainder & & \\
\hline
\end{tabular}

Here the "Remainder" tissues refer to adrenals, brain, small intestines, large intestines, kidney, muscle, pancreas, spleen, thymus, and uterus.

\section{B. Low Earth Orbit Exposure Limits}

It is very important to note that, as yet, no exposure limits have been defined for missions beyond low Earth orbit (LEO). Current limits for LEO operations limits were defined in NCRP report no. $98^{22}$ and adopted by NASA. These limits are shown in Tables 3 and 4. 
Table 3. LEO exposure limits for blood forming organs, eyes, and skin for all ages (NCRP 98).

\begin{tabular}{|l|c|c|c|}
\hline & $\begin{array}{c}\text { BFO } \\
(\mathrm{Sv})\end{array}$ & $\begin{array}{c}\text { Eye } \\
(\mathrm{Sv})\end{array}$ & $\begin{array}{c}\text { Skin } \\
(\mathrm{Sv})\end{array}$ \\
\hline Career & Table 4 & 4.00 & 6.00 \\
\hline Annual & 0.50 & 2.00 & 3.00 \\
\hline 30 Day & 0.25 & 1.00 & 1.50 \\
\hline
\end{tabular}

Table 4. LEO career BFO dose equivalent limits (Sv) (NCRP 98).

\begin{tabular}{|c|c|c|c|c|}
\hline Age & 25 & 35 & 45 & 55 \\
\hline Male & 1.5 & 2.5 & 3.2 & 4.0 \\
\hline Female & 1.0 & 1.75 & 2.5 & 3.0 \\
\hline
\end{tabular}

It should be noted here that the career limits in Table 4 are based on a 3\% excess lifetime fatal cancer risk. This means that the astronaut's risk of developing a fatal cancer during his or her lifetime is increased by no more than $3 \%$. Also, note that in addition to the limits defined in Tables 3 and 4, NASA is required to follow the principle of ALARA, keeping exposure "As Low As Reasonably Achievable."

In NCRP report no. 132, new exposure limits incorporating the new dosimetric quantities, gray equivalent and effect dose, were recommended. These limits are shown in Tables 5 and 6.

Table 5. LEO exposure limits for blood forming organs, eyes, and skin for all ages (NCRP 132).

\begin{tabular}{|l|c|c|c|}
\hline & $\begin{array}{c}\text { BFO } \\
(\text { Gy-Eq })\end{array}$ & $\begin{array}{c}\text { Eye } \\
(\text { Gy-Eq) }\end{array}$ & $\begin{array}{c}\text { Skin } \\
(\text { Gy-Eq })\end{array}$ \\
\hline Career & Table 6 & 4.00 & 6.00 \\
\hline Annual & 0.50 & 2.00 & 3.00 \\
\hline 30 Day & 0.25 & 1.00 & 1.50 \\
\hline
\end{tabular}

Figure 6. LEO career whole body effective dose limits (Sv) (NCRP 132).

\begin{tabular}{|c|c|c|c|c|}
\hline Age & 25 & 35 & 45 & 55 \\
\hline Male & 0.7 & 1.0 & 1.5 & 3.0 \\
\hline Female & 0.4 & 0.6 & 0.9 & 1.7 \\
\hline
\end{tabular}

Here, also, the career limits are based on a 3\% excess lifetime fatal cancer risk.

\section{Possible Exploration Mission Exposure Limits}

Exposure limits for missions beyond LEO have not yet been defined, but several publications ${ }^{23,24}$ have noted a large uncertainty associated with calculating cancer risk $\left(400-600 \%{ }^{20}\right)$ due to the dearth of human exposure data, especially for heavy ions. It has been recommended ${ }^{20,21}$ that fatal cancer risk be calculated directly for each mission scenario and that a $95 \%$ confidence be applied to the requirement that excess fatal cancer risk be below $3 \%$. This would have the effect of vastly lowering career exposure limits.

\section{Sample Mission Calculations}

\section{A. Long Term Lunar Surface Mission}

Analysis was performed for a six month lunar surface mission. The exposure incurred by astronauts traveling to and from the moon was not calculated, because this work had been completed in previous studies. One such previous study ${ }^{1}$ showed that for a capsule type vehicle the exposure to blood forming organs (BFO) due to GCR during solar minimum ranged from $0.39 \mathrm{cSv}$ to $0.43 \mathrm{cSv}$, which is very small compared to the exposure incurred during a lengthy surface stay and was considered negligible for this analysis. The Exploration Systems Architecture Study (ESAS) $)^{25}$ also evaluated crew exposure in a capsule type vehicle used for lunar transit. In this study, exposures due to large solar particle events were examined. Here, it was shown that for an event equivalent to 4 times the magnitude of the August 1972 event (King spectrum), the gray equivalent to BFO would range from 4.17 Gy-Eq to $4.67 \mathrm{~Gy}-\mathrm{Eq}$. It was also shown that, by adding $5 \mathrm{~g} / \mathrm{cm}^{2}(1360 \mathrm{~kg})$ of polyethylene shielding to the walls of the vehicle, these exposures could be reduced to between $1.56 \mathrm{~Gy}-\mathrm{Eq}$ and $1.73 \mathrm{gy}$-eq. Based on the extremely low probability of such a large event occurring, the ESAS team decided that it would not be necessary to carry extra 
shielding. It should be noted, however, that even though these events are very rare, these exposures vastly exceed the current LEO 30-day limit.

In the current work, the exposure during a 180-day surface stay was calculated in terms of dose equivalent to various body tissues and whole body effective dose. Here the Long Term Lunar Habitat (LTLH) was used as a representative habitat. This habitat was modeled on the L1 Lunar Mission Architecture. ${ }^{26}$ It is 23 meters tall and cylindrical. It has three floors, as shown in Fig. 6. The top floor contains the crew quarters, the middle floor a lab area, and the bottom floor an extra vehicular activity (EVA) airlock. The outer wall of this habitat is aluminum. Exposures inside this habitat were previously evaluated in reference 1, but some errors were found in the modeling of the crew quarters and the EVA airlock, so these exposures have been recalculated and the analysis has been extended to include an average dose equivalent for 42 skin points, an average dose equivalent for 32 BFO points, and an effective dose calculated with ray traces for 142 body points. These calculations were performed for both solar minimum and solar maximum environments to highlight the advantages of traveling at solar maximum. Exposures resulting from the August 1972 solar particle were also calculated.

Figure 6. View of CAD-modeled LTLH.

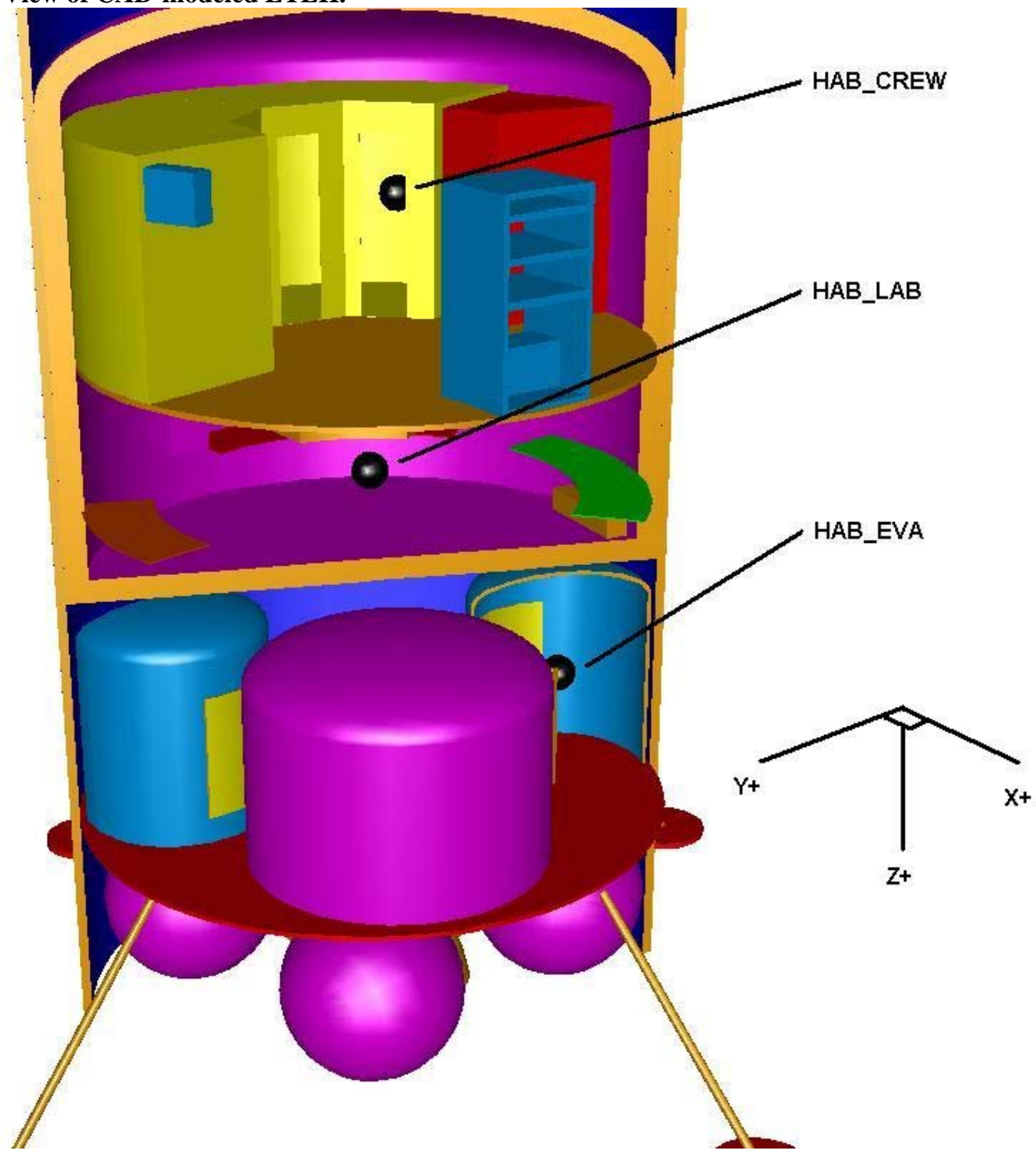

Also, these calculations were performed for two different astronaut orientations, vertical (standing) and horizontal (lying down). Previous work ${ }^{27}$ using a space station type module exposed to a proton spectrum modeling the October 1989 solar particle event showed that reorienting the astronaut within the module could change the calculated dose equivalent by a factor of two or more for some body point/habitat geometry combinations. In that 
calculation, a convolution technique was used to combine the shielding provided by the habitat with that from the astronaut's body. Using this method, the authors were able to estimate the maximum change in dose equivalent at a body location in the previous study. The use of the convolution technique, however, required the authors to model the habitat and the astronaut's body with the same material, equivalent aluminum. Here the shielding thicknesses provided by the astronaut's body were scaled by the ratio of the range of a $50 \mathrm{MeV}$ proton in aluminum to the range of a $50 \mathrm{MeV}$ proton in human tissue. In the current work, this convolution technique was not applied. Astronaut exposure was calculated in only two orientations. Therefore, the maximum change in dose equivalent and/or effective dose was not calculated. This work does, however, provide some insight into the effects of reorienting the astronaut and, because the convolution technique was not applied, the astronaut body could be modeled in a different material than the habitat, increasing the accuracy of the calculations.

In performing these calculations, a few approximations were made. First, the neutrons produced in the lunar surface were not transported through the habitat. Since low energy neutrons produce few secondaries, they provide only a small contribution to the dose equivalent. Also, the entire LTLH was converted to equivalent aluminum (the primary material) by scaling the thicknesses of non-aluminum materials using the ratios of the appropriate material densities and the astronaut body material was modeled as water (also the primary material). By converting to a two material system, dose equivalent versus shielding thickness curves could be run a-priori. These curves were then interpolated upon for the thicknesses in the ray-trace files. This method drastically reduced computation time in calculating dose equivalent at so many body points, while providing only a small error. The body point ray-traces were performed using the Computerized Anatomical Male (CAM) model originally developed by Kase ${ }^{28}$ and improved upon by Billings and Yucker. ${ }^{29}$ This model accurately models the $50^{\text {th }}$ percentile US Air Force male. However, in calculating the effective dose using Eq. 6, the dose equivalent to the various body points of like tissue type were averaged with no attempt to weight them in terms of the volume of tissue that they represented. The error introduced by this approximation is assumed to be small, however, because a large number of body points, 142, were used. Also, in calculating the dose equivalent to the various body points, each body point was assumed to be exactly located at the point ray-traced in the habitat. This produces a small error in the effective dose calculation.

Table 7. LTLH Calculated Dose Equivalent and Effective Dose, cSv (rem), in Lab.

\begin{tabular}{|l|c|c|c|c|c|c|}
\hline & \multicolumn{3}{|c|}{ Erect Astronaut } & \multicolumn{3}{c|}{ Horizontal Astronaut } \\
\cline { 2 - 7 } & $\begin{array}{c}\text { GCR } \\
\text { Solar Min }\end{array}$ & $\begin{array}{c}\text { GCR } \\
\text { Solar Max }\end{array}$ & $\begin{array}{c}\text { Aug. 1972 SPE } \\
\text { (King Spect.) }\end{array}$ & $\begin{array}{c}\text { GCR } \\
\text { Solar Min }\end{array}$ & $\begin{array}{c}\text { GCR } \\
\text { Solar Max }\end{array}$ & $\begin{array}{c}\text { Aug. 1972 SPE } \\
\text { (King Spect.) }\end{array}$ \\
\hline $\begin{array}{l}\text { Skin point 12 } \\
\text { (right arm) }\end{array}$ & 16.7 & 5.1 & 85.0 & 16.9 & 5.1 & 86.8 \\
\hline $\begin{array}{l}\text { Skin point 17 } \\
\text { (right thigh) }\end{array}$ & 15.9 & 4.9 & 78.9 & 15.9 & 4.9 & 83.7 \\
\hline $\begin{array}{l}\text { Skin point 22 } \\
\text { (chest) }\end{array}$ & 15.9 & 4.9 & 33.8 & 16.1 & 5.0 & 82.3 \\
\hline $\begin{array}{l}\text { Skin point 29 } \\
\text { (derriere left) }\end{array}$ & 15.6 & 4.8 & 75.1 & 16.3 & 5.0 & 79.9 \\
\hline Skin Average & 15.8 & 4.9 & 67.3 & 16.2 & 5.0 & 76.7 \\
\hline & & & & & & \\
\hline Eye point 1 & 16.4 & 5.0 & 70.8 & 16.7 & 5.1 & 75.1 \\
\hline $\begin{array}{l}\text { BFO point 6 } \\
\text { (sternum) }\end{array}$ & 14.7 & 4.7 & 26.5 & 14.9 & 4.8 & 28.2 \\
\hline $\begin{array}{l}\text { BFO point 8 } \\
\text { (rib) }\end{array}$ & 14.9 & 4.7 & 33.3 & 15.4 & 4.9 & 37.3 \\
\hline $\begin{array}{l}\text { BFO point 17 } \\
\text { (pelvis center) }\end{array}$ & 13.4 & 4.4 & 9.2 & 13.6 & 4.5 & 9.8 \\
\hline $\begin{array}{l}\text { BFO point 21 } \\
\text { (right femur) }\end{array}$ & 14.3 & 4.6 & 20.5 & 14.2 & 4.6 & 17.3 \\
\hline $\begin{array}{l}\text { BFO point 22 } \\
\text { (left side) }\end{array}$ & 14.7 & 4.7 & 34.5 & 15.4 & 4.9 & 41.6 \\
\hline BFO Average & 14.8 & 4.7 & 28.1 & 15.1 & 4.8 & 30.7 \\
\hline & & & & & & \\
\hline Effective Dose & 14.5 & 4.6 & 27.1 & 14.7 & 4.7 & 26.3 \\
\hline
\end{tabular}


For example, a point in the astronaut's foot cannot be occupying the same space as a point in his liver. This error should be small, however, since the habitat is large and the external environment is isotropic in $2 \pi$ solid angle and zero in the other $2 \pi$ solid angle coming from the lunar surface.

Table 8. LTLH Calculated Dose Equivalent and Effective Dose, cSv (rem), in Crew Quarters.

\begin{tabular}{|l|c|c|c|c|c|c|}
\hline & \multicolumn{3}{|c|}{ Erect Astronaut } & \multicolumn{3}{c|}{ Horizontal Astronaut } \\
\cline { 2 - 7 } & $\begin{array}{c}\text { GCR } \\
\text { Solar Min }\end{array}$ & $\begin{array}{c}\text { GCR } \\
\text { Solar Max }\end{array}$ & $\begin{array}{c}\text { Aug. 1972 SPE } \\
\text { (King Spect.) }\end{array}$ & $\begin{array}{c}\text { GCR } \\
\text { Solar Min }\end{array}$ & $\begin{array}{c}\text { GCR } \\
\text { Solar Max }\end{array}$ & $\begin{array}{c}\text { Aug. 1972 SPE } \\
\text { (King Spect.) }\end{array}$ \\
\hline Skin point 12 & 18.1 & 5.4 & 123.9 & 16.3 & 4.9 & 113.5 \\
\hline Skin point 17 & 16.1 & 5.0 & 77.7 & 13.8 & 4.4 & 42.5 \\
\hline Skin point 22 & 16.2 & 5.0 & 70.0 & 14.2 & 4.5 & 49.1 \\
\hline Skin point 29 & 17.6 & 5.3 & 110.0 & 15.9 & 4.9 & 84.9 \\
\hline Skin Average & 16.9 & 5.2 & 85.6 & 15.0 & 4.6 & 68.0 \\
\hline & & & & & & \\
\hline Eye point 1 & 17.2 & 5.2 & 72.2 & 14.9 & 4.6 & 47.0 \\
\hline & & & & & & \\
\hline BFO point 6 & 15.0 & 4.8 & 23.3 & 13.2 & 4.3 & 11.8 \\
\hline BFO point 8 & 16.3 & 5.1 & 49.0 & 15.0 & 4.7 & 49.1 \\
\hline BFO point 17 & 13.6 & 4.5 & 8.3 & 12.2 & 4.1 & 5.1 \\
\hline BFO point 21 & 14.5 & 4.7 & 17.6 & 12.9 & 4.2 & 11.9 \\
\hline BFO point 22 & 15.2 & 4.8 & 31.6 & 13.3 & 4.3 & 19.2 \\
\hline BFO Average & 15.6 & 4.9 & 34.1 & 13.9 & 4.4 & 25.3 \\
\hline & & & & & & \\
\hline Effective Dose & 15.0 & 4.8 & 26.7 & 13.2 & 4.3 & 15.7 \\
\hline
\end{tabular}

Table 9. LTLH Calculated Dose Equivalent and Effective Dose, cSv (rem), in EVA Airlock.

\begin{tabular}{|l|c|c|c|c|c|c|}
\hline & \multicolumn{3}{|c|}{ Erect Astronaut } & \multicolumn{3}{c|}{ Horizontal Astronaut } \\
\cline { 2 - 7 } & $\begin{array}{c}\text { GCR } \\
\text { Solar Min }\end{array}$ & $\begin{array}{c}\text { GCR } \\
\text { Solar Max }\end{array}$ & $\begin{array}{c}\text { Aug. 1972 SPE } \\
\text { (King Spect.) }\end{array}$ & $\begin{array}{c}\text { GCR } \\
\text { Solar Min }\end{array}$ & $\begin{array}{c}\text { GCR } \\
\text { Solar Max }\end{array}$ & $\begin{array}{c}\text { Aug. 1972 SPE } \\
\text { (King Spect.) }\end{array}$ \\
\hline Skin point 12 & 16.8 & 5.1 & 66.2 & 17.3 & 5.3 & 66.0 \\
\hline Skin point 17 & 15.2 & 4.8 & 32.5 & 16.5 & 5.1 & 60.7 \\
\hline Skin point 22 & 15.3 & 9.3 & 34.6 & 16.6 & 5.1 & 59.6 \\
\hline Skin point 29 & 15.3 & 4.8 & 42.5 & 16.0 & 5.0 & 37.5 \\
\hline Skin Average & 15.6 & 4.9 & 41.1 & 16.3 & 5.1 & 47.7 \\
\hline & & & & & & \\
\hline Eye point 1 & 15.8 & 4.9 & 35.5 & 17.2 & 5.3 & 57.2 \\
\hline & & & & & & \\
\hline BFO point 6 & 14.3 & 4.6 & 14.0 & 15.3 & 4.9 & 23.2 \\
\hline BFO point 8 & 15.0 & 4.7 & 28.9 & 15.4 & 4.9 & 22.6 \\
\hline BFO point 17 & 13.2 & 4.4 & 6.0 & 13.8 & 4.6 & 7.8 \\
\hline BFO point 21 & 14.1 & 4.6 & 13.1 & 14.5 & 4.7 & 14.6 \\
\hline BFO point 22 & 14.2 & 4.6 & 15.6 & 15.2 & 4.9 & 22.4 \\
\hline BFO Average & 14.6 & 4.7 & 18.9 & 15.2 & 4.9 & 22.0 \\
\hline & & & & & & \\
\hline Effective Dose & 14.2 & 4.6 & 15.1 & 15.0 & 4.8 & 20.2 \\
\hline
\end{tabular}

The results of the current analysis are shown in Tables 7-9 for three locations in the habitat: in the center of the lab, in the crew quarters, and in the EVA airlock. These tables show that the effective dose at solar minimum ranges from $13.2 \mathrm{cSv}$ to $15 \mathrm{cSv}$. This is well below the current LEO exposure limits for even the youngest female astronauts, but could be significant if exposure limits for lunar missions are drastically lower than current LEO limits. Tables 7-9 also show that the effective dose due to a solar particle event equivalent to the August 1972 event ranges from $15.1 \mathrm{cSv}$ to $26.7 \mathrm{cSv}$, but the average dose equivalent to $\mathrm{BFO}$ points can be as high as $34.1 \mathrm{cSv}$ and the dose equivalent to individual BFO points can be as high as $49.1 \mathrm{cSv}$. Noting that current 30 -day LEO guidelines 
limit dose equivalent to BFO to $25 \mathrm{cSv}$ and recalling the "design basis" SPE may be as large as four times the August 1972 event, these numbers are of concern. However, the effective dose and dose equivalent numbers for the EVA airlock appear to be slightly smaller, with only the dose equivalent to the point in the rib, BFO point 8 , on the vertical astronaut exceeding $25 \mathrm{cSv}$. Therefore, if the "design basis" SPE were no greater than the August 1972 event, it might be possible to use the EVA airlock in this habitat as a "storm shelter" in which the astronauts could wait out the storm. It should also be noted that if an event as large as the August 1972 event occurred near the end of the 180-day surface stay, the total mission effective dose would approach the $40 \mathrm{cSv}$ NCRP 132 LEO limit for career exposure for young female astronauts. The calculated dose equivalent values to eyes and skin do not exceed current LEO limits.

Comparison of the results for the vertical astronaut with those for the horizontal astronaut shows that the largest differences appear to be in the exposures caused by the SPE. The dose equivalent to skin point 22, on the chest, in the lab for the erect astronaut is only $41 \%$ that experienced by the horizontal astronaut and the whole body effective dose for the horizontal astronaut in the crew quarters is only $59 \%$ that of the vertical astronaut. At other body point/habitat point combinations, however, the difference between dose equivalent in the vertical astronaut and dose equivalent in the horizontal astronaut is much smaller. The larger differences must occur when lightly shielded body points are oriented so that they face lightly shielded habitat walls, since dose equivalent drops rapidly as shield thickness increases for proton environments. The complexities of the astronaut's body and the habitat geometry, however, make it difficult to guess at which points this difference will be largest without doing the calculation, especially in the case of whole body effective dose. The differences in exposure due to GCR are much smaller $(<2.5 \mathrm{cSv})$, at least for the case evaluated here. This is not surprising, because in general, shielding material is more effective in providing protection from proton environments than from heavy ions.

\section{B. Mars Missions}

Analysis was performed for a Mars transit vehicle and for the LTLH placed on the surface of Mars. This analysis assumes that the transit times to and from Mars are six months each and that there will be a one year surface stay. The GCR solar minimum environment was used as a "worst case" environment. The transit vehicle is shown in Fig. 7. The ray-traced point is in the Transhab where the astronauts will spend the majority of their time. The Transhab in Fig. 7 is the left most cylindrical object, opposite of the crew transit vehicle and directly attached to the center node. It is approximately 11.3 meters long with an outer diameter of 7.8 meters. The main structure is composed of an inner and outer inflatable layer enveloping 3 levels. The middle level houses a central water bladder for crew protection while the other two floors are geometrically identical. They consist of a

Figure 7. Mars transit vehicle.

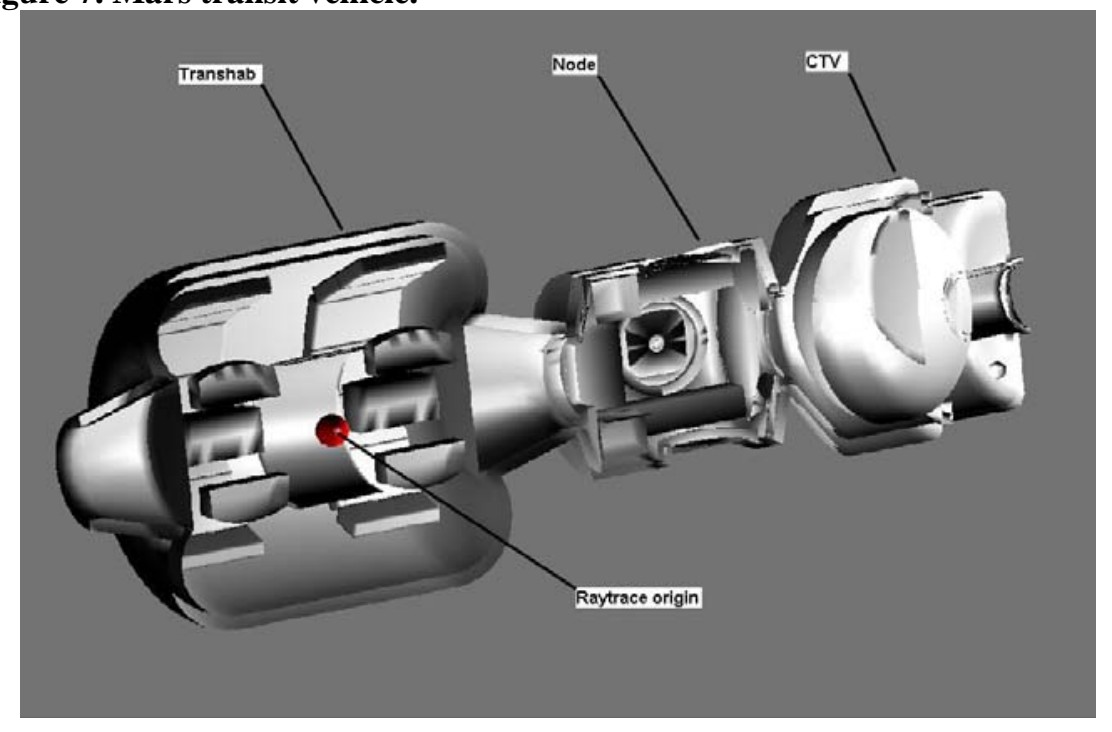
central array of three racks surrounded along the inner edge of the main structure by eight soft storage units. The ray tracing was performed with the origin inside the central water bladder on the middle floor. To streamline the transport calculation, the Transhab was converted to equivalent polyurethane using the ratios of the appropriate material densities. The ratio of the penetration of $50 \mathrm{MeV}$ protons in the materials, which has traditionally been used to convert human tissue to equivalent aluminum, was not used here for two reasons. First, most of the materials making up the Transhab have similar material characteristics and would, therefore, have similar $50 \mathrm{MeV}$ proton penetrations. Also, the $50 \mathrm{MeV}$ proton penetration is not known for every material. The calculated dose equivalent and effective dose values for this Mars transit vehicle are shown in Table 10. Note, these values are for the whole time spent in the vehicle, six months going plus six months returning. 
The dose equivalent and effective dose values for the Mars surface stay are shown in Table 11. The LTLH was modeled as described above. The Martian atmosphere was modeled as $16 \mathrm{~g} / \mathrm{cm}^{2}$ of pure $\mathrm{CO}_{2}$. As in the lunar calculation, neutrons scattered from the Martian surface were neglected. Only the vertical astronaut was considered here.

Tables 10 and 11 show that both the Mars transit vehicle and the surface habitat appear to provide enough shielding for a large SPE. It is interesting to note that the $16 \mathrm{~g} / \mathrm{cm}^{2}$ of atmosphere greatly reduces the exposure due to SPEs in the surface habitat from that seen on the lunar surface. The two tables also show that the total Mars mission effective dose is approximately $45 \mathrm{cSv}$. This number increases to approximately $51 \mathrm{cSv}$ if a solar particle event as large as the August 1972 event occurs while the astronauts are on the surface and approximately $70 \mathrm{cSv}$ if an event as large as four times the August 1972 event occurs. All of these numbers are above the NCRP 132 LEO career limit for young, female astronauts and could exceed future exploration limits based on a no more than 3\% increase in lifetime fatal cancer with a $95 \%$ confidence applied.

Table 10. Mars Transit Vehicle Calculated Dose Equivalent and Effective Dose, cSv (rem).

\begin{tabular}{|l|c|c|}
\hline & GCR (Solar Min) & Aug. 1972 SPE (King Spectrum) \\
\hline Skin Average & 29.8 & 17.9 \\
\hline Eye point 1 & 31.2 & 11.3 \\
\hline BFO Average & 26.8 & 6.7 \\
\hline Effective Dose & 25.8 & 6.2 \\
\hline
\end{tabular}

Table 11. Mars Surface Habitat Calculated Dose Equivalent and Effective Dose, cSv (rem).

\begin{tabular}{|l|c|c|c|c|c|c|}
\hline \multirow{2}{*}{} & \multicolumn{2}{|c|}{ Lab } & \multicolumn{2}{c|}{ Crew Quarters } & \multicolumn{2}{c|}{ EVA Airlock } \\
\cline { 2 - 7 } & $\begin{array}{c}\text { GCR } \\
\text { Solar Min }\end{array}$ & $\begin{array}{c}\text { Aug. 1972 } \\
\text { SPE }\end{array}$ & $\begin{array}{c}\text { GCR } \\
\text { Solar Min }\end{array}$ & $\begin{array}{c}\text { Aug. 1972 } \\
\text { SPE }\end{array}$ & $\begin{array}{c}\text { GCR } \\
\text { Solar Min }\end{array}$ & $\begin{array}{c}\text { Aug. 1972 } \\
\text { SPE }\end{array}$ \\
\hline $\begin{array}{l}\text { Skin } \\
\text { Average }\end{array}$ & 21.4 & 1.4 & 21.8 & 1.8 & 21.6 & 1.4 \\
\hline Eye point 1 & 21.4 & 1.6 & 21.8 & 2.0 & 21.6 & 1.5 \\
\hline $\begin{array}{l}\text { BFO } \\
\text { Average }\end{array}$ & 19.8 & 1.0 & 20.0 & 1.2 & 19.8 & 1.1 \\
\hline $\begin{array}{l}\text { Effective } \\
\text { Dose }\end{array}$ & 19.6 & 0.9 & 19.8 & 1.1 & 19.8 & 1.0 \\
\hline
\end{tabular}

\section{Conclusion}

A methodology for calculating radiation exposure was outlined and exposure, in terms of dose equivalent to critical tissues and whole body effective dose, was calculated for two exploration missions, a 180-day lunar surface stay and a two year mission to Mars. The results were compared to current LEO limits. This analysis showed that, if exploration mission exposure limits were similar to current LEO limits and older and/or male astronauts were chosen, then both of these mission scenarios with the vehicle and/or habitat described would be acceptable. These calculations did not, however, include exposure incurred during extra vehicular activities, which could be considerable, and due to uncertainties in our methods of quantifying exposure, it is probable that long term exploration mission exposure limits will be lower than current LEO limits. The effect of astronaut orientation within the habitat on astronaut health risk was also examined for the lunar surface habitat. These calculations showed that astronaut orientation is a more important factor in evaluating radiation shielding from large solar particle events than it is in doing a similar analysis for shielding from galactic cosmic rays.

\section{References}

\footnotetext{
${ }^{1}$ Anderson, B.M., Clowdsley, M. S., Wilson, J. W., Nealy, J. E., and Luetke, N. J., "21 ${ }^{\text {st }}$ Century Lunar Exploration: Advanced Radiation Exposure Assessment," Proceedings of the $36^{\text {th }}$ International Conference on Environmental Systems (ICES), SAE International, Warrendale, PA, 2006.

${ }^{2}$ Badhwar, G. D., and O’Neill, P. M., “An Improved Model of Galactic Cosmic Radiation for Space Exploration Missions,” Nucl. Tracks and Rad. Meas., Vol. 20, no. 3, 1995, pp. 403-410.

${ }^{3}$ Wilson, J. W., Kim, M. Y., Cucinotta, F. A., Badavi, F. F., Shinn, J. L., Tai, H., Badhwar, G. D., and Atwell, W., "Solar Cycle Variations and Application to the Space Radiation Environment," NASA TP-209369, 1999.
} 
${ }^{4}$ Reames, D. V., "Particle Acceleration at the Sun and in the Heliosphere," Space Sci. Rev., Vol. 90, nos. 3-4, 1999, pp. 413491.

${ }^{5}$ Kim, M. Y., Wilson, J. W., Simonsen, L. C., Cucinotta, F. A., Atwell, W., Badavi, F. F., and Miller, J., "Contribution of High Charge and Energy (HZE) Ions During Solar-Particle Event of September 29, 1989,” NASA TP-1999-209320, 1999.

${ }^{6}$ King, J. H., "Solar Proton Fluences for 1977-1983 Space Missions," J. Spacecraft, Vol. 11, no. 6, 1974, pp 401-408.

${ }^{7}$ Simonsen, L. C., Nealy, J. E., Townsend, L. W., and Wilson, J. W., “Space Radiation Shielding for a Martian Habitat," SAE TP 901346, 1990.

${ }^{8}$ Simonsen, L. C. and Nealy, J. E., "Radiation Protection for Human Missions to the Moon and Mars," NASA TP-3079, 1991.

${ }^{9}$ Simonsen, L. C. and Nealy, J. E., "Mars Surface Radiation Exposure for Solar Maximum Conditions and 1989 Solar Proton Events," NASA TP-3330, 1993.

${ }^{10}$ Clowdsley, M. S., DeAngelis, G., Badavi, F. F., Wilson, J. W., Singleterry, R. C., and Thibeault, S. A., "Surface Environments for Exploration," Proceedings of Space Technology and Applications International Forum - STAIF 2003,CP 654, American Institute of Physics 0-7354-0114-4/03, edited by M. S. El-Genk, 2003, pp. 1034-1045.

${ }^{11}$ Hughes, H. G., Prael, R. E., and Little R. C., "MCNPX - The LAHET/MCNP Code Merger," Los Alamos National Laboratory, LA-UR-97-4891, X-Division Research Note XTM-RN(U)97-012, 1997.

${ }^{12}$ Townsend, L. W., Miller, T. M., and Gabriel, T. A., "HETC Radiation Transport Code Development for Cosmic Ray Shielding Applications in Space," Radiat. Prot. Dosimetry, Vol. 116, nos. 1-4 pt. 2, 2005, pp 135-139.

${ }^{13}$ Fasso, A., Ferrari, A., Ranft, A., Sala, P. R., Stevenson, G. R., and Zazula, J. M., Nuclear Instruments \& Methods in Physics Research, Section A, Vol. 332, 1993, p. 459.

${ }^{14}$ Agostinelli, S., et. al., "GEANT4 - A Simulation Toolkit," Nuclear Instruments \& Methods in Physics Research, Section A,Vol. 506, no. 3, 2003, pp. 250-303

${ }^{15}$ Allison, J., et. al., "GEANT4 Developments and Applications," IEEE Transactions on Nuclear Science, Vol. 53, no. 1, pt. 2, 2006, pp. 270-278.

${ }^{16}$ Wilson, J. W., Badavi, F. F., Cucinotta, F. A., Shinn, J. L., Badhwar, G. D., Silberberg, R., Tsao, C. H., Townsend, L. W., and Tripathi, R. K., "HZETRN: Description of a Free-Space Ion and Nucleon Transport and Shielding Computer Program," NASA TP-3495, 1995.

${ }^{17}$ Wilson, J. W., Tripathi, R. K., Badavi, F. F., and Cucinotta, F. A., "Standardized Radiation Shield Design Method: 2005 HZETRN," Proceedings of the 36th International Conference on Environmental Systems (ICES), SAE International, Warrendale, PA, 2006.

18“1990 Recommendations of the International Commission for Radiological Protection,” ICRP Report No. 60, Annuals of the ICRP 21, No. 1-3, Elsevier Science, New York, 1991.

19"Limitation of Exposure to Ionizing Radiation," NCRP Report No. 116, National Council on Radiation Protection and Measurements, Bethesda, MD, 1993.

20"Radiation Protection Guidance for Activities in Low-Earth Orbit," NCRP Report No. 132, National Council on Radiation Protection and Measurements, Bethesda, MD, 2001.

21 “Operational Radiation Safety Program for Astronauts in Low-Earth Orbit: A Basic Framework,” NCRP Report No. 142, National Council on Radiation Protection and Measurements, Bethesda, MD, 2002.

22،Guidance on Radiation Received in Space Activities," NCRP Report No. 98, National Council on Radiation Protection and Measurements, Bethesda, MD, 1989.

${ }^{23}$ Cucinotta, F. A., Schimmerling, W., Wilson, J. W., Peterson, L. E., Badhwar, G. D., Saganti, P. B., and Dicello, J. F., "Space Radiation Cancer Risk and Uncertainties for Mars Missions," Radiation Research, Vol. 156, 2001, pp 682-688.

${ }^{24}$ Cucinotta, F. A., Badhwar, G. D., Saganti, P. B., Schimmerling, W., Wilson, J. W., Peterson, L. E., and Dicello, J. F., "Space Radiation Cancer Risk Projections for Exploration Missions: Uncertainty Reduction and Mitigation," NASA TP-2002210777, 2002.

25“NASA's Exploration Systems Architecture Study - Final Report," NASA TM-2005-214062, 2005.

${ }^{26}$ Geffre, J. R., "Concept Design of a Lunar L1 Gateway Outpost," Proceedings of the $34^{\text {th }}$ COSPAR Scientific Assembly and the $2^{\text {nd }}$ World Space Congress, 2002.

${ }^{27}$ Wilson, J. W., Nealy, J. E., Wood, J. S., Qualls, G., Atwell, W., Shinn, J. L., and Simonsen, L. C., "Exposure Fluctuations of Astronauts Due to Orientation," NASA TP-3364, 1993.

${ }^{28}$ Kase, P. G., "Computerized Anatomical Model Man,” Report AFWL-TR-69-161, Air Force Weapons Laboratory, Kirkland Air Force Base, NM, 2002.

${ }^{29}$ Billings, M. P. and Yucker, W. R., "Summary Final Report. The Computerized Anatomical Man (CAM) Model," Report MDC G4655, McDonnell Douglas Astronautics Company, Huntington Beach, CA, 1973. 